\title{
Dedekind and Wolffian Deductive Method
}

\author{
José Ferreirós ${ }^{1}$ (D) $\cdot$ Abel Lassalle-Casanave ${ }^{2}$
}

Accepted: 8 July 2021 / Published online: 21 January 2022

(C) The Author(s) 2022

\begin{abstract}
Dedekind's methodology, in his classic booklet on the foundations of arithmetic, has been the topic of some debate. While some authors make it closely analogue to Hilbert's early axiomatics, others emphasize its idiosyncratic features, most importantly the fact that no axioms are stated and its careful deductive structure apparently rests on definitions alone. In particular, the so-called Dedekind "axioms" of arithmetic are presented by him as "characteristic conditions" in the definition of the complex concept of a simply infinite system. Making sense of Dedekind's method may be dependent on an analysis of the classical model of deductive science, as presented by authors from the eighteenth and early nineteenth centuries. Studying the modern reconstructions of Euclidean geometry, we show that they did not presuppose deductive independence of the axioms from the definitions. Authors like Wolff elaborated a mathematics based on definitions, and the Wolffian model of deductive science shows significant coincidences with Dedekind's method, despite the great differences in content and approach. Wolff had a conception of definitions as genetic, which bears some similarities with Kant's idea of synthetic definitions: they are understood as positing the content of mathematical concepts and introducing thought objects (Gedankendinge) that are the objects of mathematics. The emphasis on the spontaneity of the understanding, which can be found in this philosophical tradition, can also be fruitfully related with Dedekind's idea of the "free creation" of mathematical objects.
\end{abstract}

Keywords Deductive methodology · Genetic definition · Kant · Free creation · Spontaneity of the understanding $\cdot$ Euclidean geometry $\cdot$ Arithmetic

\section{Introduction}

In recent years there has been a lot of discussion about the possibility of attributing a form of logicism to Dedekind, and about the details of such. ${ }^{1}$ To produce a satisfactory interpretation of Dedekind's ideas, one interesting strategy, followed by several authors, is to

\footnotetext{
${ }^{1}$ See Kitcher 1986; Stein 1988; Tait 1997; Ferreirós 1999; Shapiro 2000; Reck 2003 and 2013; Demopoulos \& Clark 2005; Benis Sinaceur 2015; Ferreirós unpub.; Klev 2017.

José Ferreirós

josef@us.es

Abel Lassalle-Casanave

abel.lassalle@gmail.com

1 Universidad de Sevilla, Seville, Spain

2 Universidade Federal da Bahia, Salvador, Brasil
} 
reconsider the presuppositions of "logic" and the meaning of "logicism" in the light of Kant's work (McCarty 1995; Ferreirós 1999 and unpub., Benis Sinaceur 2015; Klev 2017). This strategy is supported by the general influence of Kantian epistemological ideas in the nineteenth century, and even by Cassirer's reaction to Dedekind (Reck 2020).

Our focus will not be on logicism, however, but on the deductive method that is characteristic of Dedekind. Given the influence of Dedekind's mathematical ideas upon David Hilbert, it is natural to ask about similarities and differences with the latter's project in his early axiomatic period, around 1900. There is the obvious difference that Hilbert emphasizes axioms while Dedekind excludes them in arithmetic, but this difference might be less profound than may seem at first sight (Sieg 1990; Ferreirós 2009). Contrarywise, Klev (2011) has defended that profound differences exist, due to Hilbert's treatment of the basic concepts, which stands in stark contrast with Dedekind's deductive method.

In his argument, Klev considers the "classical model of deductive science" as codified in Betti and de Jong (2010). Dedekind's methodology differs from that classical model due to the absence of axioms in his presentation, even if his treatment of definitions (Erklärungen) might be compatible. Klev says Dedekind's method is "slightly idiosyncratic" due to its strong emphasis on definitions. Hilbert on the other hand insisted on treating the basic notions as schematic or variable, and took definitions in the modern sense of mere abbreviations.

The discussion can be enriched and enlightened if we disentangle some of those theses, and especially if we deepen the analysis of the "classical model" of deductive science. It is essential to consider the modern reception of Euclid's Elements and the attempts to make them compatible with Aristotelian demonstrative science (Mancosu 1996; De Risi 2016; Lassalle-Casanave 2019). Interestingly, this connects with Wolff's methodology, which can be usefully linked with Dedekind's; likewise, the former's theory of definitions can be linked (changing one important feature) with the latter's definition of natural numbers. And the matter is also connected with a thesis that Kant held constant from his pre-critical writings to the Critique and later, namely that the matter or content of mathematical concepts is not given in advance, but actively posited by the mind through definitions.

Part of our reconstruction depends on an attempt to find mathematical treatises that may compare with Dedekind's extremely careful deductive presentation. If one is strict, most textbook treatments of arithmetic fall out, since they are rather informal presentations making no attempt to follow a strictly deductive order. One is left with few previous works, among them those of Grassmann and Ohm, which however do not share the methodological structure of Dedekind. The much older work of Christian Wolff, however, stands out for the careful presentation of methodological principles in the 'Short exposition of the mathematical method' (Kurzer Unterricht von der Mathematischen Lehrart) featured in all editions of his treatise. We believe that a careful comparison of their approaches does throw some light upon Dedekind's style of exposition.

The first section of this paper will focus on early modern ideas about mathematical method, in the light of which Dedekind's methodology appears much less idiosyncratic. His work seems to bear traces of a Wolffian tradition in mathematical method. Section 2 deals with Kant's opposition to an 'analytic' conception of mathematics, and his ideas on synthesis and construction; the 'synthetic' approach seems to have been influential on Dedekind. Section 3 moves on to the details of Dedekind's method of definition-and-theorem (Erklärung-Satz), including some historical background and a critical perspective on his use of the word "definition." We catalogue the different kinds of definitions that can be found in Dedekind, and we show that one of those kinds is intimately linked with free 
interpretation of the defined notions (like in Hilbert). Finally, in Sect. 4 we analyze Dedekind's idea of "free creation" by definition of mathematical objects, which has connections to a Kantian conception of the spontaneity of the understanding.

\section{The Wolffian Methodology}

To qualify Dedekind's method as "slightly idiosyncratic", Klev takes as a model the description given by Betti and de Jong (2010). According to these authors, a system S of propositions and concepts (or terms) accords with the "classical model" when it satisfies the following seven conditions:

(1) All propositions and all concepts (or terms) of $S$ concern a specific set of objects or are about a certain domain of being $(s)$.

(2a) There are in $S$ a number of so-called fundamental concepts (or terms).

(2b) All other concepts (or terms) occurring in $S$ are composed of (or are definable from) these fundamental concepts (or terms).

(3a) There are in $S$ a number of so-called fundamental propositions.

(3b) All other propositions of $S$ follow from or are grounded in (or are provable or demonstrable from) these fundamental propositions.

(4) All propositions of $S$ are true.

(5) All propositions of $S$ are universal and necessary in some sense or another.

(6) All propositions of $S$ are known to be true. A non-fundamental proposition is known to be true through its proof in $S$.

(7) All concepts or terms of $S$ are adequately known. A non-fundamental concept is adequately known through its composition (or definition).

We are not interested here in discussing the Betti \& de Jong proposal as a whole, but only those aspects that are more related to the Early Modern tradition in mathematics. Particularly important is the link between fundamental propositions and the definitions of fundamental concepts.

Dedekind seems to comply quite well with the classical model, as defined above, except for one key absence: in his treatment of arithmetic (and set theory) there are no axioms or fundamental propositions (3a), and the theorems are grounded on the fundamental concepts (unlike $3 \mathrm{~b}$ ). The proposal of Betti \& de Jong may give rise to the impression that, according to the classical model, axioms or Grundsätze must be considered deductively independent of the definitions, but, as we shall show, this is far from true. In the Early Modern period, and even more so in the Germanic area, the "classical model" often included a most intimate deductive connection between axioms and definitions; sometimes this led to axiomless presentations. This shows that Dedekind's methodology (perhaps oldfashioned for its time) was far from idiosyncratic.

In fact, the sources considered by Betti and de Jong (2010)_Aristotle, Port-Royal, Bolzano-are insufficient with a view to characterize the classical model, especially with respect to the foundations of mathematics (which at the time still meant above all geometry). It is of great importance to examine the reconstructions of Euclid's Elements, often done in the spirit of a new presentation in line with Aristotelian ideas about deductive science. De Risi (2016) has called attention to the importance of this tradition. Although his 
work focuses on the many and variegated axioms offered in the course of that reconstructive activity, to fill alleged deductive gaps in the Elements, one can also read:

It should at least be noted, however, that many mathematicians in the Early Modern Age believed that axioms and postulates were in fact provable from definitions. (De Risi 2016, 602)

In Germany the surviving Scholastic idea that all the axioms should ultimately be proven from the definitions also engendered several axiomless textbooks which enjoyed a wide diffusion (the most important representatives of these being Christian Wolff's, Andreas Segner's and Wenceslaus Karsten's German and Latin treatments of elementary mathematics). (De Risi 2016, 601)

Consider the influential case of Christian Wolff. ${ }^{2}$ Elementa matheseos universae is a text where we find a careful deductive structure based entirely on definitions. Wolff (1732, 7) writes about axioms and postulates as derived from definitions:

$\S 30$. Anything that is immediately deduced from them, which is contained in a Definition, is called Axiom, if it enunciates that something applies or does not apply to some thing. And it will be called Postulate, if it affirms or denies that something can be done. For example, from the genesis of a circle it follows that all lines traced from center to periphery are equal to each other, even if they are placed in different sites. This proposition is counted among the axioms. By the same definition one understands that at any point and with any interval a circle can be described - which proposition is placed among the postulates. ${ }^{3}$

Here considered is the famous genetic definition of a circle, an example that traverses the Modern literature on definitions and their relation to axioms and postulates. Wolff (1732, $\S 18,5)$ had previously explained that a real definition

is a distinct notion from the genesis of the thing, i.e., exposing the way in which it can be done. Thus in Geometry the circle, if conceived as described by the movement of a straight line around a fixed point.

This definition of circle was employed by Hobbes, Spinoza, Tschirnhaus, Leibniz, etc., ${ }^{4}$ but also by Borelli, who authored what was perhaps the most influential reconstruction of Euclidean geometry in Modernity. He writes in Euclides Restitutus (Borelli 1658, 9):

The figure described by the revolution of a finite straight line on a plane, around any one of its extreme points at rest, until it returns to the same place from which it moved, is called Circle. And the point at rest is called Center, and the line traced by the other extreme point is named Circumference.

Like Wolff later, Borelli $(1658,14)$ considers it an axiom that the lines which join the circumference with the centre are all equal-because this follows immediately from the genetic definition of a circle. About the axioms, Borelli $(1658,14)$ states:

\footnotetext{
${ }^{2}$ For a general account of the Wolffian method, see Dunlop (2013) and Cantù (2018).

${ }^{3}$ Compare the German version in Wolff (1710), §. 27, which coincides in all the key aspects. The German words used by Wolff are "Erklährung" for definition and "Grundsatz" for axiom.

4 According to De Risi $(2015,20)$, the definition is due to pseudo-Heron of Alexandria in Geometrica. Felgner (2020) emphasizes the role of Tschirnhaus as intermediary, as an immediate influence on Wolff.
} 
The axioms (Axiomata) are, as stated [in the Preface], speculative propositions, or theorems, that due to their utmost evidence do not require a demonstration, for immediately, once the terms are known, the understanding will necessarily assent to them, and for this reason they are counted among the indemonstrable principles.

This notion of "immediacy" must be understood in connection with another basic aspect of the Aristotelian model of science: the idea that proofs are sequences of syllogisms that start from principles. This tradition distinguished between mediate inferences which involve a middle term (and thus syllogistic reasoning) ${ }^{5}$ and immediate inferences (with no middle term involved). All the authors we have mentioned assume this 'canonical' idea of proof, even if they admit that, for brevity's sake, not all proofs will be presented that way. Thus, Wolff $(1732$, Sect. 45,10$)$ writes:

Therefore, the demonstrations of mathematicians are an accumulation of enthymemes. So all of them conclude by the force of syllogisms, while omitting premises, which occur spontaneously to the reader who meditates or are brought back to memory by citations.

Also Borelli expresses himself similarly in Euclides Restitutus $(1658,19)$ : the process of demonstrations "is not exposed by syllogisms in order to avoid prolixity, for no-one proceeds always by syllogisms of the first figure," opting instead for enthymemes (minor premiss is "omitted for the sake of brevity").

In such cases the propositions (theorems) follow in a mediated way, not immediately as with axioms. Another revealing example of the relevance of definitions, and of the general traits of these 'Aristotelian' reconstructions of geometry, can be found in the Euclides Reformatus due to Marchetti in 1709. Like Borelli, Marchetti assumes the definition of straight line due to Archimedes, as the shortest distance between two points. ${ }^{6}$ In the Elements, Euclid proves in I.20 that in a triangle two sides are greater than the third, but Marchetti includes that statement as his Axiom I.22. The reason (Marchetti 1709, 11-12) is that Euclid, not defining the straight as shortest line (brevissima), must then prove I.20but when we assume the Archimedean definition, the statement follows immediately and is thus an axiom.

Although Wolff identifies real definitions with the genetic ones, the reduction of axioms to definitions does not presuppose this identification, in the tradition we are considering. Also nominal definitions (based on the enumeration of characteristic notes of a thing; Wolff 1732, Sect. 17, 5) can be the basis for reduction. Other authors, such as Leibniz, besides considering nominal definitions, allow for real definitions which are not genetic, e.g., Euclid's definition of circle. ${ }^{7}$ Indeed, one can hardly understand Archimedes' definition of a straight line as being genetic - it rather offers a characteristic defining property, without offering means for construction. In any event, the general thesis is that definitions express an elucidation of concepts such that some other propositions follow deductively,

\footnotetext{
5 Also the sense of 'syllogism' was broader than the strict Aristotelian sense, including propositional inferences and even some relational inferences; we do not enter into such details, but we mention the point again below.

6 See On the Sphere \& the Cylinder.

7 The matter is complex. A real non-constructive definition would consist in the complete analysis of a concept into its (essential) simple components, which would likewise provide an "internal" proof of its consistency. The obvious difficulty of such an analysis leads Leibniz to privilege, from the viewpoint of epistemology of mathematics, the constructive real definitions (see De Risi 2015, 35-40).
} 
but immediately. These may be called axioms (as in the authors previously mentioned) or may be presented as immediate consequences as happens in the axiomless treatises of Kastner or Segner (1773). The general thesis is valid in any event, for both traditions, and it implies that the weight of the deductive structuring falls upon the definitions. ${ }^{8}$

Summing up, a Wolffian conception of a deductive system $S$ would preserve elements (1), (2b) and (4)-(7) of the "classical model" as presented previously, but it would modify points (2a) and (3). Indeed, (2a) there are in $S$ a number of so-called fundamental concepts (or terms); but they are regarded as expressing in distilled form the whole content of the system $S$. As regards (3a), the so-called fundamental propositions or axioms, these may or may not be of focal importance in the system; but the axioms are conceived as immediate consequences of the fundamental concepts involved in them-as an immediate expression of the content of the fundamental concepts. Thus, one could also say that ( $3 \mathrm{~b}$ ) all propositions of $S$ follow from or are grounded in (or are demonstrable from) the fundamental concepts, either immediately or syllogistically.

When things are understood this way, with theorems being derived syllogistically, and provided a certain conception of the definitions (as analytical statements of characteristic properties), we have ingredients that may give rise to a kind of logicistic thesis. It gives in any event an apriorist thesis, which would become logicistic if the basic notions underlying it were shown to be logical ones.

\section{Some Ideas of Kant and Wolff}

There is a conception of mathematics that Kant fights against, in the Critique of Pure Reason. This conception may not coincide with Wolff's, but it is certainly represented by many authors in the Wolffian tradition. Its main tenets can be briefly formulated as follows: (a) mathematical concepts have a previously given content, which their definitions make explicit through an analysis of such content; (b) the axioms follow immediately and deductively from the relevant definitions, hence ultimately emerging from conceptual analysis; (c) any proof can be reformulated syllogistically, starting from the axioms. One could enter into much more detail about the topic, but for our purposes it is better to remain with this basic scheme.

Of those three theses, Kant is happy to accept the third: any science, not just mathematics, can be presented in syllogistic reconstruction. This does not imply a diminished role of intuition in mathematical proofs; probably it has to be understood as a matter of mere formal presentation, but the premises would be grounded in intuition. We showed in the previous section how it was assumed that proofs can be reconstructed syllogistically, and Kant calmly repeats the statement: "Syllogistic method is that according to which a science is presented in a chain of inferences" (Kant 1992a, 639). ${ }^{9}$ Nevertheless, Kant rejects a),

\footnotetext{
8 The most important eighteenth century exception to this rule is Lambert (1786), as De Risi emphasizes.

9 We know that the logical reconstruction of Euclidean proofs requires a more powerful logic, since relational propositions are being proven, but in practice the notion of syllogism employed in early Modern times was wide enough to include some relational inferences. One should not confuse two issues: it is one thing to have an adequate concept of logical form, and another to refuse to acknowledge valid inferences. That any proposition of Euclidean plane geometry can be presented as a sequence of syllogisms (even prop. I.32 that the angle sum in a triangle is two straight angles) is a thesis that either Kant nor anyone else doubted at the time.
} 
and for that reason will reject also b) in the following sense: the concepts of mathematics are posited by their definitions; the axioms do follow immediately from definitions, though not deductively, but rather by construction. Interestingly, already Wolff insisted that the content of mathematical concepts is not antecedently given but posited by their definitions, $a b$ ovo. Wolff's 'genetic' definitions are not nominal ones, and they posit or generate content-in his view, they are not based on analysis.

In general, a definition consists in this: "to exhibit originally the exhaustive concept of a thing within its boundaries" (A 727/B 755; Kant 1998, 637). Only in mathematics is such a condition fully satisfied, for in mathematics, the definitions of fundamental concepts are constructions of concepts (A 730/B 757; Kant 1998, 638). ${ }^{10}$ As Kant writes in Jäsche's Logic, all mathematical definitions are genetic, ${ }^{11}$ i.e., real in the strict sense of Wolff. ${ }^{12}$ Even though, strictly speaking, only in mathematics there are definitions, Kant uses also a different terminology: in philosophy we have analytical definitions, but the mathematical ones are synthetic (A 730/B 758; Kant 1998, 639).

Only mathematics has axioms, according to Kant, and they follow by the construction of the concepts: mathematics "is capable of axioms, e.g. that three points always lie in a plane, because by means of the construction of concepts in the intuition of the object it can connect the predicates of the latter a priori and immediately" (A 732/B 760, Kant 1998, 640). It has been observed that Kant regarded as 'axioms' propositions that are not in Euclid, e.g. "that in a triangle two sides together are always greater than the third" (A 25/B 39, Kant 1998, 159). This is Proposition I.20 in Euclid, ${ }^{13}$ but we have seen that this proposition is an axiom in Marchetti (1709), founded upon the definition of the straight line as the shortest line. According to Kant, this cannot be analytic, but is a synthetic statement, as the concept of shortest cannot be obtained by analysis of the qualitative concept of straight: "Help must here be gotten from intuition, by means of which alone the synthesis is possible" (B 16; Kant 1998, 145); namely that, of all lines between two points, the shortest one has the character of being straight. As Kant says, one cannot think of any line "without drawing it in thought, i.e., successively generating all its parts from one point," and thereby sketching an intuition (A 162/B 203; Kant 1998, 287). ${ }^{14}$

That the sum of two sides of a triangle is greater than the third follows constructively, not deductively, from the relevant definitions, since the concepts of this judgment (subject concept and predicate concept) are connected by the construction. And this is not only a priori but also an immediate connection, as happens also with the principle that the straight is the shortest line between two points. Similarly, all mathematical axioms are "derived from intuition and indeed derived a priori with apodictic certainty" (A 25/B 39, Kant 1998, 159).

\footnotetext{
${ }^{10}$ Kant's first Critique is quoted following the usual convention, designating the first and second editions with A and B. Translations of Kant's works are cited as usual, by year and page.

11 Kant 1992a, 634: "A definition is genetic if it yields a concept through which the object can be exhibited a priori in concreto; all mathematical definitions are of this sort."

12 On real definitions of circle and parallel in Kant and the modern tradition, see Heis (2014) and De Risi (2015).

13 Friedman $(1992,83)$ throws doubt on the usual identification of fundamental propositions (Grundsätze) and axioms in Kant, since I.20 is "not an axiom in Euclid, but a basic (and therefore fundamental) theorem." However, Kant's examples of axioms are taken from modern reconstructions of the Elements. Incidentally, in Lambert (1771), §71, it is an axiom that three points always lie on a plane.

${ }^{14}$ What is the genetic definition of straight line that Kant is considering? It might well be Wolff's definition, that the motion of a point engenders a line: "If the point in its motion from one place to another advances so that its direction is never changed, then it describes a straight line" (Wolff 1710, 104).
} 
As one can see, Kant was well aware of the tradition of reconstructions of the Elements that we examined above. ${ }^{15}$ It is in relation to such reconstructions, that one should understand the statement that characterizes his conception of mathematics: "mathematical cognition [is rational cognition] from the construction of concepts... to construct a concept means to exhibit a priori the intuition corresponding to it" (A 713/B 741; Kant 1998, 630).

Let us emphasize that Kant kept constant throughout his life the thesis, that the definition of a mathematical concept is not a result of analysis. In the 1764 Inquiry concerning the distinctness of the principles of natural theology, he states:

There are two ways in which one arrives at a general concept: either by the arbitrary combination of concepts, or by separating out that cognition which has been rendered distinct by means of analysis. Mathematics only ever draws up its definitions in the first way. For example, think arbitrarily of four straight lines on a plane surface so that the opposite sides are not parallel to each other. Let this figure be called a trapezium. The concept which I am defining is not given prior to the definition itself; on the contrary, it only comes into existence as a result of that definition. Whatever the concept of a cone may ordinarily signify, in mathematics the concept is the product of the arbitrary representation of a right-angled triangle which is rotated on one of its sides. In this and in other cases the definition obviously comes into being as a result of synthesis. (Kant 1992b, 248)

But while in the Inquiry, as Kant emphasizes, an arbitrary, logically possible composition of concepts is held sufficient to introduce mathematical content, ${ }^{16}$ in the Critique there is a rejection of that central 'rationalist' thesis. Identifying the 'rationalism' that was fought by Kant (but which he once defended) is relevant to an adequate understanding of the critical project.

While Dedekind's conception of arithmetic (and pure mathematics) is a reaction against the Kantian thesis of the intuitiveness of mathematical notions, in many points he was picking up Kantian notions. A clear example is the understanding of axioms in the old, preHilbertian sense: they are "synthetic a priori principles," based on intuition and "immediately true" according to Kant (A 732/B 760, Kant 1998, 640). In all likelihood, Dedekind understands axioms in the Kantian sense, and for this reason he aims to show that arithmetic is axiomless ${ }^{17}$; otherwise it would not be purely logical. On this point, his understanding coincides fully with Frege's (see the well-known correspondence with Hilbert, in Frege 1950). But there is more: we shall see that Dedekind shares a deep conviction of the creativity or spontaneity of the understanding. This was a basic tenet of Wolffian rationalism, especially as regards mathematical notions, but in a different sense it is central to the Kantian viewpoint: e.g., concepts involve "the unity of the action of ordering different representations under a common one" (A 68/B 93; Kant 1998, 205). In Wolff's mathematics we find already the idea of genetic definition of concepts, but with Kant this is clarified and modified with his characteristic thesis of the 'construction in intuition'. Dedekind may have

\footnotetext{
${ }_{15}$ For more details on the topic of this and the previous section, see Lassalle Casanave (2019), ch. 3 and especially ch. 5 .

${ }^{16}$ Kant 1992b, 252, 254, 256, 264.

17 See Ferreirós 1999, 247, Ferreirós forthcoming. In the context of geometry, Dedekind does recognize axioms, but not so for the real numbers which are developed "purely logically", through the phenomenon of cuts "in its logical purity" (Dedekind 1888, first preface).
} 
shared this idea early on, but his development took him farther and farther from it, to end up emphasizing a totally different, purely logical kind of "construction" (non-temporal, not intuitive, based merely on "laws of thought"). ${ }^{18}$

\section{Erklärung and Satz in Dedekind's Zahlen}

Dedekind's logicism interfered with his understanding of deductive method. There is evidence that, because he regarded arithmetic as purely logical, he therefore viewed it as an axiomless science. His notion of an axiom was basically Kantian: an axiom being a synthetic a priori proposition, it cannot be purely logical, but displays intuitive content. Thus, for philosophical reasons, Dedekind took the classical model of Wolff one step further, and he avoided axioms altogether.

Some of the main evidence for our previous statement is the following. A manuscript on (projective) geometry, written at some point during the 1860 s or 70 s, discusses the "presuppositions" of geometry and its relations to the science of numbers ${ }^{19}$; here Dedekind gave definitions and axioms for projective space understood as a point-set. This is in stark contrast with his approach to the foundations of arithmetic, where axioms are conspicuously absent (Dedekind 1888). Again, in his paper on the irrational numbers, he emphasized that the continuity of the geometric line cannot be demonstrated: "The assumption of this property of the line is nothing else than an axiom ... by which we introduce in thought continuity into the line" (Dedekind 1872, 323/772). By contrast, Dedekind had discovered long before 1872 that the continuous number-domain can be defined, without any appeal to axioms or intuitions, by expanding the number system "through a finite set of simple steps of thought" (Dedekind 1888, 340/793). Notice that the core of Dedekind's classical paper (1872) is the formulation of a definition of continuity (not an 'axiom'), completely independent from any appeal to geometry. The whole science of numbers does not rest on axioms, in the above sense, but merely on logical principles.

Here, as in other central traits of his position, Dedekind seems to have stood close to Frege's viewpoint. For it is well known that Frege understood by axiom "a thought whose truth is certain [feststeht]" and which cannot be proven by a logical chain of inferences (Frege 1903, 319). He added to this that the intuition [Anschauung] is usually regarded as the source of the truth of the axioms of geometry ${ }^{20}$ : Frege was more of a strict Kantian, while Dedekind was Riemannian on this point.

\subsection{Immediate Consequences}

Implicit in that way of speaking about logic in contrast to intuition, is the typical nineteenth-century - and quite Kantian—conception of Logic as the science of the pure laws

\footnotetext{
18 Curiously, Cassirer will take advantage of this element in Dedekind's work and use it to state that Kant had been right claiming the centrality of 'construction' (Reck 2020,345), but obviously this is a sleight of hand.

19 In his Nachlass, Cod. Ms. Dedekind XII, 3; see Ferreirós 1999, 238, and http://kalliope-verbund.info/ DE-611-HS-3234701 (accessed May 12, 2020).

20 Yet on a related point, Frege had quite a different methodology: the logical principles must be formulated as "basic laws," since it would be inadequate to consider the definitions as basic principles; definitions are "arbitrary stipulations" and thus quite different from any assertion (Frege 1903, 320).
} 
of thought (reinen Denkgesetze, Dedekind 1888, 335/791). If arithmetic has to be proven purely logical, it must be established that it does not rest on axioms, i.e., on a priori intuitive propositions.

The Wolffian deductive method may seem particularly adequate, from this point of view, and Dedekind adheres to it strictly. He probably was well acquainted with this kind of deductive presentation from readings of German textbooks in his youth (see below), perhaps even textbooks of Wolff himself. ${ }^{21}$ ) The first theorems in Zahlen appear as immediately evident, they are presented as immediate consequences that follow from definitions. Let us consider a couple of examples.

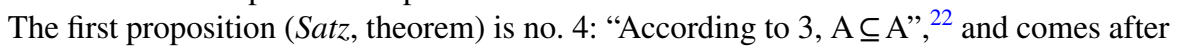
the definition of part of, the inclusion relation (no. 3). It is an immediate inference, needing no intermediate steps. The same happens with no. 9: "The sets A, B, C . . are parts of $\mathbf{U}(\mathrm{A}$, B, C...)"-Dedekind indicates that this follows immediately from Def. 8 (of "composite set", the union) and Def. 3 (see 1888, 346/797). Also no. 18 is given as an immediate consequence of Def. 17 of the intersection or "community" of sets.

All of these examples are from Sect. 1 of Zahlen, "Sets of elements", which presents the basic "logic" of sets. But we keep finding similar things in later sections. E.g. the very important Sect. 4 deals with "Mapping of a set into itself" [Abbildung eines Systems in sich selbst], and here we find two definitions of "chain". The first, rather trivial one, is no. 37: " $\mathrm{K}$ is called a chain if $\mathrm{K} \subseteq \mathrm{K}$ " (where $\mathrm{K}$ ' is the image of $\mathrm{K}$ under a given mapping, $\varphi$ ). $\varphi$ being explicitly assumed to be an inner map $\varphi: S \rightarrow S$ (see 1888, 351-352/803), no. 38 is an immediate consequence: " $\mathrm{S}$ is a chain".

The second definition of chain, no. 44, introducing the "chain of [a set] A," is of much greater importance, being the foundation for the reduction of the principle of mathematical induction to his basic framework. Incidentally, when dealing with this notion Dedekind proves to be well acquainted with the practice of modern axiomatics, even if he does not call it axiomatics. (The chain of $\mathrm{A}$ is designated $\mathrm{A}_{\mathrm{o}}$ or more explicitly $\varphi_{\mathrm{o}}(\mathrm{A})$. Regarding this "very important concept," Dedekind proves three propositions, and then comments in Note 48 that the notion of the chain $\mathrm{A}_{\mathrm{o}}$ is "completely characterized" by those three propositions: $45\left(\mathrm{~A} \subseteq \mathrm{A}_{\mathrm{o}}\right), 46\left(\varphi\left(\mathrm{A}_{\mathrm{o}}\right) \subseteq \mathrm{A}_{\mathrm{o}}\right)$, and 47 (if $\mathrm{A} \subseteq \mathrm{K}$ and $\mathrm{K}$ is closed under $\varphi$, then $\left.A_{o} \subseteq K\right)$. This is a nice instance of axiomatic analysis.)

Although readers may want to revisit Dedekind's text for themselves, the examples just given should suffice to show that Dedekind's deductive organization follows the Wolffian model.

Incidentally, there are additional points where a comparison between Dedekind's work and Wolff's is quite suggestive. The absolutely general notion of a thing (Ding) that we find in Dedekind's Zahlen (1888) is in line with the views of Leibnizian and Wollfian philosophy. ${ }^{23}$ According to Leibniz, an "ens" or Ding is anything whose concept can be represented as possible; and this is enthusiastically taken up by Wolff: "Ding is all that can

\footnotetext{
${ }^{21}$ Gauss (who was a model for Dedekind, and who studied in the same institutions) was very well acquainted with the textbooks of Wolff; see Reich $(2006,77)$.

22 "A 3 A" is the symbolism actually employed by Dedekind; we replace it by the usual one in order to increase readership. We do similarly with the sign for union.

23 Dedekind (1888, 796-797), no. 1: "I understand by thing [Ding] every object of our thought ... A thing is completely determined by all that can be affirmed or thought concerning it." One is also reminded of Frege's views about abstract objects, his distinction between actual [wirklich] and non-actual objects.
} 
be, whether it is actual [wirklich] or not." ${ }^{24}$ The link with Dedekind's notion, and with the Hilbertian conception of mathematical existence, is difficult to deny.

Furthermore, Wolff's definition of number is peculiarly close to Dedekind's definition-not of number, but of set. Wolf defines number as follows: "If one brings together many single things of a kind [viel einzele Dinge von einer Art zusammennimmt], therefrom emerges [entstehet] a number" (Wolff 1710, 34). And this is Dedekind on sets: "It happens very frequently that different things $a, b, c \ldots$ are considered from a common point of view, are brought together in the mind [im Geiste zusammengestellt], and we say that they form a set $[$ System] $S "(1888,344 / 797)$. In our view, Wolff was jumping too quickly from the formation of a set, to the notion of its number (of elements). Dedekind's way of proceeding is more rigorous, step by step.

\subsection{Kinds of Definitions}

The above is not to say, of course, that Dedekind's deductive system of propositions (Sätze) and definitions (Erklärungen) was particularly brilliant or commendable. We think it is not. In our view the definitions of Dedekind's Zahlen come in different kinds, playing quite different roles in his deductive writing. Upon analysis, some of his definitions are nominal or analytical, while others may be more rightly regarded as creative or synthetic (more on this below); besides, there is the case of the most basic notions, set or System and map or Abbildung, one of which is presented by an Erklärung, but not the other (breaking symmetry). This is quite unpardonable in a mathematician so careful and logically-minded as Dedekind.

It would have been more adequate to avoid the rubric 'Erklärung' in both of these cases, because set-building and mapping are taken to be the two basic "faculties" or "capacities" $[\text { Fähigkeiten }]^{25}$ of the understanding which lay the basis for the whole system. They are indispensable for thinking in general, i.e. for logic (Dedekind 1888, 336/791), they are absolutely primitive conceptions. One may elucidate what is understood by set and map, and one may introduce nominal definitions for the technical terms and signs to be employed. But the so-called 'definition' of Abbildung, like the introduction of the notion of set (System), have a totally different role to play than the other definitions given by Dedekind. Here we seem to be in agreement with Benis-Sinaceur:

Dedekind takes those concepts as resulting from two grounding operations, namely making a System from a multiplicity, and representing a thing by a thing, which are both taken to be 'logical' in the sense that: (i) they are more general than the usual arithmetic operations, and (ii) they constitute the creative power of the mind. (BenisSinaceur 2015, 3)

We move on to a second kind, to what are properly speaking definitions. Nominal definitions abound in Dedekind's text, examples being: part of, union, intersection, image, similarity of a map, etc. For instance, a map is similar or (in our terms) injective when images $\varphi(a)=\varphi(b)$ only if $a=b$, i.e., different elements are assigned different images (Dedekind 1888, no. 26). The reader may see other examples from the original text.

\footnotetext{
${ }^{24}$ See Vernünftige Gedanken (Wolff 1752), §16. For Wolff, "ens" is that which can exist, i.e. whose existence is not repugnant or contradictory.

25 Dedekind 1888, 335/791, 337/792, 344/797; cf. also 343/796.
} 
But one can find also a third kind of definitions, which are treated very differently; we have called them synthetic or even creative definitions, and they introduce free interpretation of terms. Importantly, these are not genetic definitions in the sense of Wolff and Kant, since there is no role here for intuition or construction in an intuitive sense (although they may be synthetic definitions in a sense admitted by Kant, at least in the 1764 Inquiry). ${ }^{26}$ Of this kind are the most important mathematical ingredients in Dedekind's work: the concepts of 'infinite set', of 'simply infinite system', of 'the chain of a set'.

Consider the definition of "simply infinite system" (no. 71): this is a structure (intuitively, the natural-number structure) defined to be the "chain" of a base element, via an injective map $\varphi$ (in fact, a map that orders the set, a successor function). The definition depends essentially on the basic notion of mapping; it combines the previously defined notions of inner map, $\varphi$-chain, and similarity. ${ }^{27}$ It is creative, in the sense that it carves out theoretical content in a novel way, demanding a proof of existence (in the sense of logical possibility). It is also the basis for Dedekind's presentation of natural numbers as "free creations" of the mind, which is another reason for our terminology.

Dedekind acknowledges the need to establish the existence of such sets; this underscores the creative character of this definition, calling for a "logical proof of existence", as he says in letter to Keferstein, 1890:

After the essential nature of the simply infinite system, whose abstract type is the number sequence $N$, had been recognized in my analysis (articles 71 and 73), the question arose: does such a set exist at all in the realm of thought [Gedankenwelt]? Without a logical proof of existence it would always remain doubtful whether the notion of such a system might not perhaps contain internal contradictions. Hence the need for such proofs (articles 66 and 72 of my essay). (van Heijenoort 1967, 101)

Indeed proposition no. 72 presents a rather straightforward proof that every infinite set (in the sense of def. 64) contains a simply infinite system. ${ }^{28}$ The idea that a purely logical definition may be ampliative, introduce new content and thus extend our knowledge, was not unheard of at this time. ${ }^{29}$

Klev (2011) was right to call attention to the fact that Dedekind's basic notions have a fixed interpretation - sets are always sets in the usual intended sense, and the same goes for maps. But he does not comment that this is not valid for the definitions we have just analyzed. The creative definitions do allow for multiple interpretation, and so we find here another facet of Dedekind's work that prefigures Hilbert's, one that is central to Dedekind's structuralism.

\footnotetext{
26 See the 1764 quote above, where Kant emphasizes that mathematical definitions are never the result of analysis, but are drawn up by "arbitrary combination of concepts.".

27 The notion of "the chain of A" (no. 44) presupposes that of map: the -chain of a set A, is the minimal closure of A under the map (see Dedekind 1888, no. 44).

28 Also the definition of finite and infinite (no. 64) is based on the combination of four concepts introduced in previous Erklärungen, and calls for a "logical proof of existence": first Dedekind proves that a unitary set is finite (no. 65), and then that there are infinite sets (no. 66). On the famous proposition 66 see, among other works, Ferreirós forthcoming, Klev (2018).

29 See Frege 1884, §88: "the more fruitful type of definition is a matter of drawing boundary lines that were not previously given at all. ... The conclusions we draw from it extend our knowledge, and ought therefore, on Kant's view, to be regarded as synthetic; and yet they can be proved by purely logical means, and are thus analytic. The truth is that they are contained in the definitions, but as plants are contained in their seeds, not as beams are contained in a house. Often we need several definitions for the proof of some proposition, which consequently is not contained in any one of them alone, yet does follow purely logically from all of them together."
} 


\subsection{Three Historical Facts}

Some historical evidence, briefly presented here, will contribute to a better appreciation of the sense and context of Dedekind's methodological choice. The following points make clear that the Wolffian method was not forgotten even in the second half of the nineteenth century, especially as regards arithmetic.

Firstly, in the context of arithmetic, there was an uninterrupted sequence of textbooks that offered axiomless presentations of the discipline. This includes the work of Segner (1773), and even more advanced nineteenth-century works such as Martin Ohm's Versuch eines vollkommen consequenten Systems der Mathematik (1822) and Grassmann's Lehrbuch (1861). It has been argued that Ohm's System had a significant impact upon later, more successful attempts to establish the foundations of arithmetic, particularly on Weierstrass and Dedekind. In any event, Ohm (1822) is the first treatise in which one finds the characteristic 'genetic presentation' of the number systems, starting from the naturals and working by successive amplification. ${ }^{30}$ As regards Grassmann (1861), his work was very careful and influential, being refereed and used by authors such as Schroeder, Cantor, Peano. Given that Grassmann was a significant promoter of the axiomatic method, it is noteworthy that his presentation works entirely by Erklärungen and features no axiom. ${ }^{31}$

Secondly, this way of proceeding, in arithmetic, is quite consistent with Kant's approach to the matter. Kant had a restrictive understanding of arithmetic as a mere art of calculation (Rechen-Kunst). ${ }^{32}$ We cannot enter into the complexities of Kant's vision of arithmetic, but there is a tension in the Critique between a "purely intellectual" conception of number, and the "scheme of quantity" according to which number is "a representation that summarizes the successive addition of one unit to another (homogeneous) one" (A 142/B 182; Kant 1998, 274). This is illustrated by a passage from a letter to Schultz:

the science of numbers, notwithstanding succession, which every construction of magnitudes requires, is a pure intellectual synthesis that we represent to ourselves in thoughts. But insofar as the specific magnitudes (quanta) are to be determined in accordance with this, they must be given in such a way that we can apprehend their intuition successively; and thus this apprehension is subject to the condition of time. (Kant 1999, 285)

Kant acknowledges arithmetic as a science, but the arithmetical judgements which he considers as prototypical (in the Critique or the letter to Schultz) are merely elementary numerical equations, such as $7+5=12$ or $3+5=2^{3}$. Although a priori and intuitive, such judgments are not axioms, for they are not universal judgments, and there would be infinitely many of them. Geometry has axioms, according to Kant, but not arithmetic. ${ }^{33}$

\footnotetext{
30 The amplification is guided by the inverse operations of subtraction, division, etc., which are required to be of general application, i.e., the domain is required to be closed under the inverse operations. Thus, from the naturals we are led to the integers (closed under subtraction), and then the rationals (closed under division), and so on.

31 Not even the axiom of induction for natural numbers, although Grassmann (1861) made constant use of induction; nor can one find an axiom of completeness for the real numbers.

32 See Letter to Schultz, 25 November, 1788; Kant 1999, 284.

33 "But concerning magnitude (quantitas), ... although various of these propositions are synthetic and immediately certain (indemonstrabilia), there are nevertheless no axioms in the proper sense." (B 204 A 163-164; Kant 1998, 288); On other aspects of Kant's vision of arithmetic, see Parsons 1984, Shabel 1998, Sutherland 2006.
} 
The generations of Ohm, Grassmann and Dedekind contributed to a significant change in the conception of arithmetic, by focusing on the general laws of associativity, commutativity, etc., and by adopting a more theoretical understanding of the subject (which combines elementary arithmetic with number theory), including an emphasis on mathematical induction. There is quite a strong shift from the discipline as treated by Wolff or Segner, who regarded it as an art of calculation (Rechen-Kunst), to the post-Gaussian conception of the subject.

Thirdly, since Dedekind's aim was to present arithmetic as merely a part of logic, it is relevant to consider the question of deductive method in the domain of logic. Here follows what Ernst Schroeder had to say on the topic, in his important work on the Circle of operations of the logical calculus (Operationskreis des Logikkalkuls, 1877). Schroeder chose to introduce the basic propositions of the Boolean system as axioms, but he wrote:

All theorems of our discipline are intuitive; they appear as immediately evident, as soon as brought to consciousness, and therefore the statements which are here presented as axioms could also, with right, be given as consequences that follow immediately with the definitions. (Schroeder 1877,4 )

As one can see, despite employing the opposite method, Schroeder explicitly acknowledges the Wolffian methodology as a viable option. One should add that Schroeder was strongly influenced by Grassmann, and his works were particularly valued by Dedekind. ${ }^{34}$

Linking the questions just discussed with Kant, one can say that, for authors who agreed with the Kantian characterization of axioms as true, synthetic a priori propositions, it was inadequate to regard the basic propositions of logic as axioms in the strict sense. And Kantianism was quite widespread in nineteenth century Germany.

\section{Dedekind's "Free Creation"}

The idea that mathematical objects are "free creations" of the intellect or the mind was one of the most cherished convictions of Dedekind, a constantly recurring thought throughout the years, from 1854 to 1911 (from age 23 to age 80). The Kantian principle of the spontaneity of the understanding has the potential of shedding light upon Dedekind's famous talk of creative powers.

One of the most significant features of Kant's critical philosophy is the distinction between sensibility and understanding, sensible intuitions being based "on the receptivity of impressions" while concepts are "grounded on the spontaneity of thinking" (concepts involve "the unity of the action of ordering different representations under a common one", A 68/B 93; Kant 1998, 205). There can be no object without the understanding creatively uniting the manifold (of empirical data) into a unity, the thing. But also mathematical objects are given through a "synthesis" which at once produces the concept of that thing. ${ }^{35}$ Such ideas can be

\footnotetext{
34 As we know from publications and manuscripts. See the second preface to (1888), 343/795, and the 1897 paper in Werke vol. 2, 112-113; as for manuscripts see Dugac 1976, 272, and Cod. Ms. Dedekind III, 30 (comments on the Vorlesungen). The high esteem was reciprocal, see Schroeder (1890/95), vol. 3.

35 Kant 1992b, 264: "mathematics arrives at its concepts synthetically; it can say with certainty that what it did not intend to represent in the object by means of definition is not contained in that object. For the concept of what has been defined only comes into existence by means of the definition; the concept has no other significance at all apart from that which is given to it by the definition."
} 
usefully considered when interpreting Dedekind's appeals to the "creative power" [Schöpferkraft] of the mind "to create from determinate elements a new determinate, their set, that is necessarily different from each of these elements" (1911 Preface to 1888, 343/796).

\subsection{Set-Construction as Synthesis}

From Dedekind's perspective, two of the most basic intellectual abilities are the faculty of setting (making a plurality of things into a whole) and the faculty of mapping, representing. These are the basis for his reorganization of pure mathematics, and the basis for his logicism. He understands those notions, isolated by means of a careful reconstruction of classical mathematics, to be basic logical faculties or abilities of the mind-in a move that seems to be influenced by a Kantian perspective. The first of those abilities is very close to the idea, emphasized by Kant often, of the active role of the understanding in the synthesis of plurality (the manifold) into a unity.

We have taken the liberty of introducing that neologism, setting, in part to stress the parallelism with its accompanying notion of mapping, in part to underscore the Kantian background. These abilities are at play in the understanding and capture a significant part of its function. Sets are a product of the capacity of the understanding to reunite a collection of things into a whole, ${ }^{36}$ "creating" a new thought-object. Maps or functions are a product of our ability to establish a correspondence between a given set of things and their images, i.e., a representation or Abbildung (Dedekind 1888, 335/791). The view that classes or sets, regarded as extensions of concepts, are purely logical entities, was well grounded in a tradition that had recently been reinvigorated by Boole, Schroeder and others (see Ferreirós 1996).

Using the terminology of Wolff and Kant again, the set is a Gedankending, a thoughtobject, an ens rationis, completely determined by its extension, by its elements. Needless to say, such an intellectualized approach to mathematics, based on "mere concepts (although not contradictory)" and not based on intuition, deviates from the essence of the Kantian conception of mathematics. It seems plausible that Dedekind stood closer to the rationalists than to Kant, on this crucial point, and thus he rejected any requirement of exhibiting in concreto, in intuition, contents adequate to the general concept. ${ }^{37}$ But this position deviates from Kant, one might say, from within-it goes back to an intellectual conception of mathematics that Kant himself held early on, in the pre-critical period, around 1764.

\subsection{Construction and Acts of Creation}

The construction of a concept that Kant is always emphasizing is, likewise, an activity: the "(spontaneous) production of a corresponding intuition" (Kant 2002, 287; see Shabel 2003). Mathematics therefore requires the possibility of certain spontaneous acts; and the

\footnotetext{
36 To consider "different things, $a, b, c, \ldots$ from a common point of view, associat[ing them] in the mind," i.e. the understanding, so that they "form a set $S$ " (Zahlen, no. 2). Such a set $S$ (or aggregate, manifold, class) "as an object of our thought is likewise a thing" (Dedekind 1888, 344/797). See Ferreirós (forthcoming) and Klev (2017) for further reasons why this way of understanding Dedekind is adequate.

37 While proving the independence of the category of totality from those of unity and plurality, Kant establishes that there are no infinite totalities (B 111; Kant 1998, 215): "the concept of a number ... is not always possible wherever the concepts of multitude and the unity are (e.g., in the representation of the infinite)".
} 
possibility of such an act is guaranteed by a "postulate". We postulate e.g. that one can add a unit to any given number: the act ' +1 ' can always be performed anew, iteratively, and each time it yields the successor of any given number. ${ }^{38}$ In Dedekind's terms, it yields the "creation" of the successor $n$ ' of a given number $n$.

Interestingly, corresponding thoughts can be found in early manuscripts of Dedekind, which we tentatively date to 1860 or thereabouts. ${ }^{39}$ In Arithmetische Grundlagen (Cod. Ms. Ded. III, 4) Dedekind begins right away with "Erschaffung der Zahlen":

Creation of the numbers: to each number $a$, there is built by the act +1 the following number $a+1$. - They all fall by complete induction. ${ }^{40}$

Then comes the Erklärung of addition, which is a recursive definition, and proofs of associativity and commutativity of that operation. Likewise, in $\$ 5$ we find the definition of multiplication, recursive, and proofs of conmutativity, distributivity and associativity. Another attempt on the same topic, bearing exactly the same title, begins with this sentence (which perhaps may be left untranslated):

$$
\text { Schöpfungsact } 1 ; 1+1=2 ; 2+1=3 ; 3+1=4 \ldots \text { Zahlen }(\text { Ordinal })
$$

Thus the ordinal numbers, the basis of Dedekind's reorganization of the foundations of the number system, were regarded as the outcome of successive acts of intellectual creation.

Many years later, in 1888, the "creation" involved in how the understanding gives rise to the natural numbers was presented in a different way. The idea of successive acts was replaced by a more static approach, where the image $\varphi(N)$ of the whole set is given 'all at once' by the successor function, the map $\varphi$ defined on $N$. This is the perspective of Was sind und was sollen die Zahlen? (1888). Involved were basic logical procedures, having to do with sets and maps, employed in the formulation of a complex definition of simply infinite system. Finally, one "entirely neglect[s] the special character of the elements, only retaining their distinguishability and taking into account only the relations to one another in which they are placed by the ordering mapping." (1888, 360/809) Then the elements of a simply infinite system are called "natural numbers or ordinal numbers," and "with reference to this liberation of the elements from every other content (abstraction)" Dedekind feels justified in calling the numbers "a free creation of the human mind." 41

Let us offer another example of the modifications in the way the idea is presented, and the changes of emphasis. Take the 1872 idea that we create new objects, the irrational

\footnotetext{
38 This seems to be a reasonable reconstruction of the idea of number as a pure scheme of magnitude; however, Kant also says that elementary equations are postulates: "The judgment " $3+4=7$ " does seem to be merely a theoretical judgment, and, objectively regarded, that is what it is; but subjectively regarded, the sign "+" signifies the synthesis involved in getting a third number out of two other numbers, and it signifies a task to be done, requiring no rule prescribing its solution and no proof. Consequently the judgment is a postulate." (Letter to Schultz, Kant 1999, 284) On arithmetical equations as immediate resolutions of problems (postulates), see Lassalle-Casanave 2019, 179-181.

39 See Ferreirós 1999, 222-223. Our dating considers that his definition of the real numbers stems from 1858, and also that Vorlesungen über Zahlentheorie (1863) already features a sophisticated discussion of induction.

40 "Erschaffung der Zahlen: auf jeder Zahl $a$ wird durch den Act +1 die folgende Zahl $a+1$ gebildet. Verfall aller durch vollständige Induction."

41 In recent years there have been two attempts to reevaluate and reconstruct Dedekind abstraction: Reck (2003) and Sieg \& Morris (2018). Both emphasize the structuralist bent of the idea, but explain its ontological assumptions differently; Reck's approach makes the 1888 idea appear closer to the stronger 1872 formulation.
} 
numbers, to correspond to certain cuts on the system of rational numbers: this seems to be a more substantial step, ontologically, than the logically-regimented step of abstraction that was invoked in $1888 .{ }^{42}$ One may call the 1888 version of 'creation' Pickwickian, considering its pale nature compared to the earlier creative acts. ${ }^{43}$

Thus one can see in Dedekind's manuscripts and publications an evolution which, starting from a position that seems close to Kant (acts of creation of concrete numbers, apparently in temporal succession), eventually ends up in a much more abstract, timeless, static and purely logical perspective. Yet the active role of the understanding and its "abilities" continues to be of focal importance. The Kantian perspective helps also clarify an important aspect: when Dedekind speaks of free creation, this is not meant in the sense of any kind of arbitrary use of mental images or representations-but what may be described as autonomous productions of the understanding. Freedom means autonomy, not arbitrary conventions.

\subsection{Necessity}

In order to reinforce the interpretation just proposed, let us here remind the reader of another constant feature of Dedekind's ruminations on the "free creations" of the mind. We mean that the creative powers of the intellect are constantly associated with necessity (Notwendigkeit), in a kind of dialectics of freedom and necessity that is quite characteristic. This can be seen already from the very first appearance of the idea.

In 1854, Dedekind was defending the view that mathematics, like other sciences, presents progress through "the introduction of new functions," the discovery of new truths, the revision of definitions in order to expand their reach, and so on. There is a general law that "the further development of the discipline has always an innovative feed-back effect [neubildend zurïckwirkt] upon the system," i.e. on its general organization (Dedekind 1854, 430). The discovery of new truths motivates the reconstruction of the basic definitions, and "[t]his twisting and turning of the definitions, for love of the newly found laws or truths, constitutes the greatest art of the systematician". But in the next paragraph, Dedekind goes on to insist that the case of mathematics is special, insofar as "this expansion of the definitions leaves no room for arbitrariness, but follows with compulsory necessity [mit zwingender Notwendigkeit]" $(1854,430) .{ }^{44}$ On the next page, we read that arithmetic requires to "reproduce anew the whole realm of numbers" through each of the inverse operations, and this "leads to the necessity of creating new classes of numbers" (Dedekind 1854, 431).

Around the time of Zahlen, in letters to Weber, we find again "the character of inner necessity" vindicated in the same context in which there's talk about the "creative powers" that humans possess, both in the material realm (trains, telegraphs) and particularly in intellectual affairs (see Werke III, 488, 489). Commenting on Kummer's "Schöpfung" of the ideal numbers, Dedekind insists that he had always "regarded it as completely justified, provided it is carried out with rigor" (op. cit., 490). The proviso is very characteristic, and

\footnotetext{
42 But even in 1872 , all properties of the irrationals were determined by properties of cuts on $\mathbf{Q}$, there was a strict reduction even on the face of the "creation" of new objects.

43 Maybe one could see here an evolution from early Romantic ideas, perhaps grounded in concrete philosophical works (Lotze? Fries?), to later more 'logicistic' conceptions ... But we shall not try to follow this course here.

44 The idea that he presents at this time is a kind of principle of permanence of equivalent forms, reminiscent of Ohm and Peacock before, or Hankel later.
} 
rigor, quite obviously, is associated with logic and necessity. The same association is found again in the 1911 Preface that we quoted at the start of this section: the "inner harmony" of logic, our "creative power," and the "necessary"-all together in a single sentence.

It is thus natural to interpret Dedekind's idea of numbers as free creations of the mind, not in the sense of arbitrary products of the imagination, but in a Kantian sense of spontaneous products of the intellect. Freedom here, linked with necessity, displays the autonomy and spontaneity of the understanding.

\section{Conclusion}

To recapitulate, we have found that different aspects of Wolff's methodology, and of Kant's philosophy, have significant potential to throw light on Dedekind's ideas and methods, as laid out in his foundational work-especially in his mature work, Was sind und was sollen die Zahlen?

Far from being idiosyncratic, as Klev states, the Erklärung-Satz deductive method was characteristic of significant works in the eighteenth century (Wolff, Segner, Karsten), following a model that can be found already in the seventeenth (Borelli, Marchetti, Tschirnhaus). It's also characteristic of a whole tradition of treatises on the elements of arithmetic, including Ohm and Grassmann in the nineteenth century (at least insofar as they feature no axioms). It is tempting to speculate that Dedekind may have had direct knowledge of Wolff's treatises, which enjoyed such a wide diffusion, and especially of the 'Short exposition of the mathematical method' (Kurzer Unterricht von der Mathematischen Lehrart) featured in all editions and versions of Wolff's treatise $(1710 ; 1732)$, abridged or not.

Without making such a claim, ${ }^{45}$ the important idea is that there existed a long tradition of Wolffian treatises, and an even longer tradition of emphasis on definitions as the ultimate source of mathematical truths, to which Wolff himself belongs. Even in the absence of precise knowledge of how exactly Dedekind got acquainted with this tradition, the evidence strongly suggests that he knew it well.

Also important is to realize how strong the tradition of links between mathematics and philosophy was in the German-speaking area. One author that is little known today, but who was widely read and used as a reference then, is Georg S. Klügel. His influential Mathematisches Wörterbuch is interesting from the viewpoint of philosophical remarks about mathematics, and the author himself was (like Wolff or Lambert) a typical example of the enlightened thinker who combines philosophy, science and mathematics. ${ }^{46}$ Other prominent examples are Bolzano, Gauss, and Riemann; the latter two were decisive influences upon Dedekind's way of thinking. Dedekind received this kind of heritage, and he points to it, with characteristic modesty and restraint, when he writes in the Preface to (Dedekind $1888,791)$ that "no academic philosophical or mathematical knowledge is required" for studying his work.

\footnotetext{
45 For which there is no direct evidence: we lack information about Dedekind's library, unlike e.g. the case of Gauss, who studied carefully the works of Wolff and Lambert. We know that he probably used the library at the Collegium Carolinum in Braunschweig, which was quite good; his father was professor and administrator at the Collegium Carolinum, which also suggests rich library holdings going back to the eighteenth century.

${ }^{46}$ Interestingly, Klügel (1805, vol. 2, 131) writes, in Wolffian spirit, that a mathematical definition "only needs to be proven, insofar as one has to show that the form of magnitude which is there found is possible." Compare our discussion of Dedekind's creative definitions in Sect. 3.2.
} 
The logicism of Dedekind can be understood against the background of Kantian and Wolffian epistemology, being of course closer to the rationalists, and far from Kant's strictures about the intuitive content of admissible concepts. Dedekind's emphasis on the "creative power" of the human mind can be regarded as a 'naturalized' version of the Kantian insistence on the productivity and spontaneity of the understanding. ${ }^{47}$

Let us finally remark that we have criticized the various forms of "definition" one can find in Zahlen, noting their differences. We argued that the basic capacities of 'setting' and 'mapping' - according to his own standpoint—can be invoked, but not defined; and we showed that 'creative' definitions do introduce free interpretation-a key feature of Hilbert's later conception of deductive science.

Dedekind's booklet was described as "epoch-making" by such people as Hilbert and Weyl, thinking about its deductive contents, ${ }^{48}$ but not because of the basic skeleton of its deductive presentation. At this level, Dedekind proved to be more a somewhat old-fashioned mathematician than a forward-looking logician. However, the important details of his analysis of the science of numbers offered an impressive contribution to the reduction of the number system to general set theory, and in the process he contributed significantly to the practice of modern axiomatics and structuralism. His analysis was indeed regarded as axiomatic, in retrospect, despite the fact that Dedekind himself-due to his epistemological project-was interested in showing that arithmetic has no axioms (in the Kantian sense).

In this case, like many others, one must distinguish carefully the intentions and projects of the author, from the context of reception of the work. Many authors prefer to simplify their study of Dedekind's epoch-making work, and they openly apply an axiomatic interpretation to it. While we acknowledge that one can read Dedekind's work from an axiomatic perspective, we should be careful to acknowledge that a measure of anachronism is thereby introduced. Some authors (e.g. Sieg and Schlimm 2005) impose an axiomatic structure upon Dedekind's work without even pausing to acknowledge that he avoided any explicit appeal to axioms in arithmetic. ${ }^{49}$ In doing this, an important part of Dedekind's philosophical and methodological options are cut out—one forgets the peculiar nature of the logical "faculties" which he appeals to, the Kantian remnants in his approach, and one leaves out completely the fact that he viewed definitions as the real source of arithmetical content.

Acknowledgements We thank Davide Crippa, Elías Fuentes Guillén, Vincenzo De Risi and Hourya Benis Sinaceur for their helpful comments and suggestions; two unknown referees also contributed to improving the final version. We wish to acknowledge the financial support of the Spanish Ministry of Science (Project FFI2017-84524-P), the National Council for Scientific and Technological Development, Brazil (CNPQ, Projects 304206/2019-9 and 424126/2018-4), and of the Universidad de Sevilla (grant from Plan Propio) for making possible the research stay of the second author.

Open Access This article is licensed under a Creative Commons Attribution 4.0 International License, which permits use, sharing, adaptation, distribution and reproduction in any medium or format, as long as you give appropriate credit to the original author(s) and the source, provide a link to the Creative Commons licence, and indicate if changes were made. The images or other third party material in this article are included in the article's Creative Commons licence, unless indicated otherwise in a credit line to the material. If material is not included in the article's Creative Commons licence and your intended use is not

\footnotetext{
47 This in turn might explain why Cassirer reacted so positively to Dedekind's ideas, see Reck 2020.

48 Hilbert in 1904: "This work was epoch-making, but ..." (van Heijenoort 1967, 166; see also a 1926 statement on p. 375); Weyl (1918, footnote to p. 16) notes "the great historical significance of this work of Dedekind for the development of mathematical thinking."

49 Underlying this is the tension between the pre-1900 understanding of the word axiom, and the new sense of the word promoted by Hilbert and his school.
} 
permitted by statutory regulation or exceeds the permitted use, you will need to obtain permission directly from the copyright holder. To view a copy of this licence, visit http://creativecommons.org/licenses/by/4.0/.

\section{References}

Benis Sinaceur, H. 2015. Is Dedekind a logicist? Why does such a question arise? In Functions and generality of logic, ed. H. Benis Sinaceur, et al. Berlin: Springer.

Betti, A., and W. R. de Jong. 2010. The classical model of science: A millennia-old model of scientific rationality. Synthese 174: 185-203.

Borelli, G. A. 1658. Euclides restitutus, sive prisca geometriae elementa. Pisa: F. Onofrio. https://archi ve.org/details/bub_gb_wH59yvSiY7IC/page/n6/mode/2up.

Cantù, P. 2018. Mathematics: Systematical concepts. In Handbuch Christian Wolff, ed. R. Theis and A. Aichele, 357-379. Berlin: Springer Verlag.

De Risi, V., ed. 2015. Mathematizing space: The objects of geometry from antiquity to the early modern age. Cham: Springer.

De Risi, V. 2016. The development of Euclidean axiomatics. Archive for History of Exact Sciences 70: 591-676.

Dedekind, R. 1854. Über die Einführung neuer Functionen in der Mathematik [Habilitation lecture]. In Dedekind's Gesammelte mathematische Werke Vol. 3 (1930/32, reprint New York, Chelsea, 1969), 428-438. English trans. in [Ewald 1996], vol. 2.

Dedekind, R. 1872. Stetigkeit und irrationale Zahlen. Braunschweig, Vieweg. References to Dedekind's Gesammelte mathematische Werke Vol. 3 (1930/32, reprint New York, Chelsea, 1969), 315-334. English trans. in [Ewald 1996], vol. 2. We give the page numbers of both the German edn. (Werke) and Ewald's translation.

Dedekind, R. 1888. Was sind und was sollen die Zahlen?, Braunschweig, Vieweg. References to Dedekind's Gesammelte mathematische Werke Vol. 3 (1930/32, reprint New York, Chelsea, 1969), 335390. English trans. in [Ewald 1996], vol. 2. We give the page numbers of both the German edn. (Werke) and Ewald's translation.

Dedekind, R. Cod. Ms. Dedekind. Scientific legacy or Nachlass kept at the Niedersächsische Staats- und Universitätsbibliothek (Handschriftenabteilung) in Göttingen.

Demopoulos, W., and P. Clark. 2005. The logicism of Frege, Dedekind and Russell. In Oxford handbook of philosophy of mathematics and logic, ed. S. Shapiro. Oxford: Oxford University Press.

Dugac, P. 1976. Richard Dedekind et les fondements des mathématiques. Paris: Vrin.

Dunlop, K. 2013. Mathematical method and Newtonian science in the philosophy of Christian Wolff. Studies in History and Philosophy of Science Part A 44 (3): 457-469.

Felgner, U. 2020. Philosophie der Mathematik in der Antike und in der Neuzeit. Berlin: Springer.

Ferreirós, J. 1996. Traditional logic and the early history of sets, 1854-1908. Archive for History of Exact Sciences, 50: 5-71.

Ferreirós, J. 1999. Labyrinth of thought. A history of set theory and its role in modern mathematics. Basel: Birkhäuser.

Ferreirós, J. 2009. Hilbert, logicism, and mathematical existence. Synthese 170 (1): 33-70.

Ferreirós, J. (forthcoming) On Dedekind's Logicism. To appear in A. Arana \& C. Alvarez (eds.), Analytic Philosophy and the Foundations of Mathematics. Palgrave Macmillan, in print.

Frege, G. 1903. Über die Grundlagen der Geometrie. Jahresbericht Der Deutschen Mathematiker-Vereinigung 12 (1903): 319-324.

Frege, G. 1884. The foundations of arithmetic. Oxford: Basil Blackwell.

Friedman, M. 1992. Kant and the exact sciences. Cambridge, MA: Harvard University Press.

Grassmann, H. G. 1861. Lehrbuch der Arithmetik für höhere Lehranstalten. Berlin: Enslin.

Heis, J. 2014. Kant (versus Leibniz, Wolff, and Lambert) on Real Definitions in Geometry. Canadian Journal of Philosophy 44 (5-6): 605-630.

van Heijenoort, J., ed. 1967. From Frege to Gödel: A source book. Cambridge, MA: Harvard University Press.

Kant, I. 1992a. Lectures on Logic (The Cambridge Edition, J. Young, ed.). Cambridge University Press.

Kant, I. 1992b. Theoretical philosophy, 1755-1770 (The Cambridge Edition, D. Walford, ed.). Cambridge: Cambridge University Press.

Kant, I. 1998. Critique of Pure Reason (The Cambridge Edition), P. Guyer and A. Wood, eds. Cambridge: Cambridge University Press.

Kant, I. 1999. Correspondence (The Cambridge Edition), ed. A. Zweig. Cambridge: Cambridge University Press. 
Kant, I. 2002. Theoretical philosophy after 1781 (The Cambridge Edition), ed. H. Allison \& P. Heath. Cambridge: Cambridge University Press.

Kitcher, P. 1986. Frege, Dedekind, and the philosophy of mathematics. In Frege Synthetized, ed. L. Haaparanta and J. Hintikka, 299-343. Dordrecht: D. Reidel.

Klev, A. 2011. Dedekind and Hilbert on the foundations of the deductive sciences. The Review of Symbolic Logic 4 (04): 645-681.

Klev, A. 2017. Dedekind's Logicism. Philosophia Mathematica 25 (3): 341-368.

Klev, A. 2018. A road map of Dedekind's Theorem 66. HOPOS 8: 241-277.

Klügel, G. S. 1805. Mathematisches Wörterbuch, Vol. 2 (E to I), Leipzig: Schwickert.

Lambert, J. H. 1771. Anlage zur Architectonic. Vol. 1. Riga.

Lassalle Casanave, A. 2019. Por construção de conceitos: em torno da filosofia kantiana da matemática, Rio de Janeiro: Ed. PUC-Rio; São Paulo: Edições Loyola.

Mancosu, P. 1996. Philosophy of mathematics and mathematical practice in the seventeenth century. Oxford: Oxford University Press.

Marchetti, A. 1709. Euclides reformatus, Livorno: Celsi.

McCarty, D. C. 1995. The Mysteries of Richard Dedekind. In From Dedekind to Gödel, ed. J. Hintikka. Dordrecht: Kluwer.

Ohm, M. 1822. Versuch eines vollkommen consequenten Systems der Mathematik, Lehrbuch der Arithmetik, Algebra und Analysis. Berlin: T. H. Riemann.

Parsons, C. 1984. Arithmetic and the Categories. Topoi 3 (2): 109-121.

Reck, E. H. 2003. Dedekind's structuralism: An interpretation and partial defense. Synthese 137: 369-419.

Reck, E. H. 2013. Frege, Dedekind, and the origins of logicism. History and Philosophy of Logic 34: 242-265.

Reck, E. H. 2020. Cassirer's reception of Dedekind and the structuralist transformation of mathematics. In The prehistory of mathematical structuralism, ed. E. H. Reck and G. Schiemer. Oxford: Oxford University Press.

Reich, K. 2006. Carl Friedrich Gauss (1777-1855). In Conferències FME: Volum III. Curs Gauss, 2005-2006, 75-86. Univ. Politècnica de Catalunya. Open Access. https://upcommons.upc.edu/handle/2117/81172.

Schroeder, E. 1877. Der Operationskreis des Logikkalküls. Leipzig: Teubner.

Schroeder, E. 1890/95. Vorlesungen über die Algebra der Logik, 3 vols., Leipzig: Teubner. Reprint New York: Chelsea, 1966.

Segner, J. A. 1773. Anfangsgründe der Arithmetic, Geometrie und der geometrischen Berechnungen. Halle: Renger.

Shabel, L. 2003. Mathematics in Kant's Critical Philosophy. London: Routledge.

Shapiro, S. 2000. Frege meets Dedekind: A neologicist treatment of real analysis. Notre Dame Journal of Formal Logic 41 (4): 335-364.

Sieg, W. 1990. Relative consistency and accessible domains. Synthese 84, 259-297. In The architecture of modern mathematics, ed. J. Ferreirós and J. Gray, 339-368. Oxford: Oxford University Press.

Sieg, W., and R. Morris. 2018. Dedekind's structuralism: Creating concepts and deriving theorems. In Logic, philosophy of mathematics, and their history: Essays in honor W.W. Tait, ed. E. Reck. London: College Publications.

Sieg, W., and D. Schlimm. 2005. Dedekind's analysis of number: Systems and axioms. Synthese 147 (1): $121-170$.

Stein, H. 1988. Logos, logic, and logistiké: Some philosophical remarks on nineteenth-century transformation of mathematics. In History and philosophy of modern mathematics, ed. W. Aspray and Kitcher. Minneapolis: University of Minnesota Press.

Sutherland, D. 2006. Kant on Arithmetic, Algebra, and the Theory of Proportions. Journal of the History of Philosophy 44 (4): 533-558.

Tait, W. W. 1997. Frege versus Cantor and Dedekind: On the concept of number. In Frege, Russell, Wittgenstein: Essays in early analytic philosophy, ed. W. W. Tait, 213-248. Lasalle: Open Court Press.

Weyl, H. 1918. Das Kontinuum: Kritische Untersuchungen über die Grundlagen der Analysis, Leipzig: Veit. Reprint New York, Chelsea, undated.

Wolff, Chr. 1710. Anfangs-Gründe Aller Mathematischen Wissenschafften. Vol. 1. Halle (Saale): Renger. Numerous later editions, e.g. the fifth: Halle 1737, and editions in Vienna 1763 and 1775.

Wolff, Chr. 1732. Elementa matheseos universae. Geneva, Bousquets. Latin version of the previous work, with numerous editions from 1713 to 1754. https://archive.org/details/elementamatheseo01wolf/page/ n15/mode/2up.

Wolff, Chr. 1752. Vernünftige Gedanken von Gott, der Welt und der Seele des Menschen. Halle (Saale): Regner.

Publisher's Note Springer Nature remains neutral with regard to jurisdictional claims in published maps and institutional affiliations. 